\title{
ĐÁNH GIÁ TÍNH KHẢ THI CỦA PHẪU THUẠTT NỘI SOI TRUNG THẤT SINH THIÊTT Ở BỆNH NHÂN CÓ HỘI CHỬNG CHÈN ÉP TĨNH MẠCH CHỦ TRÊN
}

\author{
Nguyễn Viết Đăng Quang*, Ngô Quốc Hưng *, Vũ Hĩu Vĩnh *
}

\section{ĐẠT V VẤN ĐỀ:}

Hồi cứu mô tả cắt ngang có nhóm chứng. Từ $10 / 2010$ đến $02 / 2015$, chúng tôi nghiên cứu được $81 \mathrm{BN}$ được phẫu thuật nội soi trung thất sinh thiết, được chia làm 2 nhóm, Nhóm 1: $42 \mathrm{BN}$ không có hội chứng chèn ép TMCT, nhóm 2: 39 có hội chứng chèn ép TMCT. Chúng tôi ghi nhận kết quả như sau : có sự tương đồng giới tính giữa 2 nhóm, nhóm 2 có tuổi trung bình cao hơn $(51.7$ \pm 12.6 vs $39.7 \pm 17.9, \mathrm{p}=0.03)$. Trên CTScan ngực: nhóm 2 có kích thước $\mathrm{u}$ lớn hơn $(8.67 \pm 3.0$ vs $3.77 \pm 2.1, \mathrm{p}=0.006$ ), xâm lấn mạch máu $(\mathrm{p}=0.001)$ và có giới hạn không rõ $(\mathrm{p}=0.001)$ nhiều hơn nhóm 1 . Về bản chất khối u, nhóm 1 chủ yếu là hạch $(32 / 42 \mathrm{TH})$, nhóm 2 chủ yếu là u trung thất $(35 / 39 \mathrm{TH})$. Về phẫu thuật, ghi nhận khả năng sinh thiết trọn ở nhóm 1 cao hơn $(\mathrm{p}=$ 0.001 ), có sự tường đồng giữa 2 nhóm về các yếu tố trong phẫu thuật: Thời gian phẫu thuật( $p=0.27)$, lượng máu mất $(p=0.71)$. Nhóm 2 có $1 \mathrm{TH}$ chảy máu nhiều cần mở ngực cầm máu. Kết quả phẫu thuật : có sự tương đồng giửa 2 nhóm : thời gian thở máy $(\mathrm{p}=0.21)$, số ngày nằm viện $(\mathrm{p}=0.83)$ và tỉ lệ sinh thiết thất bại $(\mathrm{p}=0.51)$.

Nội soi trung thất sinh thiết ở $\mathrm{BN}$ có hội chứng chèn ép TMCT là khả thi, có độ an toàn và biến chứng thấp. Tỉ lệ sinh thiết thành công ở nhóm $\mathrm{BN}$ có chèn ép TMCT tương đương với các nhóm BN khác.

\section{EVALUATED THE PROPABILITY OF MEDIASTINOSCOPY IN THE PATIET} HAD SUPERIOR VENA CAVA SYNDROME

\section{SUMMARY:}

A retrospective study from 10/2010 to 02/2015 with compare 2 group : Group 1: 42 patients had not SVCS; Group 2: 39 patients had
SVCS. We found that the sex was the same in 2 group, group 2 had the mean age higher $(51.7 \pm$ 12.6 vs $39.7 \pm 17.9, \mathrm{p}=0.03)$. In chest Ctscan, group 2 had size of tumor bigger $(8.67 \pm 3.0$ vs $3.77 \pm 2.1, \mathrm{p}=0.006$ ), more invased strustures around $(p=0.001)$ and unclear margin $(p=0.001)$ than group 1 . In the pathology, group 1 was a large of malignant and tuberculosis lymp nodes (32/42), beside that, group 2 was the most malignant thymoma (35/39). In the operation, we found that group 1 had the rate of completed biopsy more than group $2(\mathrm{p}=0.001)$, but the time of operation $(p=0.27)$ and the blood loss $(p=0.71)$ were the same. We recognized that there was no different significantly between 2 group in : the time of mechanical ventilation support $(\mathrm{p}=0.21)$, the days of hopitalized $(\mathrm{p}=0.83)$ and the rate of biopsy failure $(\mathrm{p}=0.51)$.

Mediastinoscopy in the patient had SVCS were safe and efficiency. The rate of biopsy failure was the same another group.

Key word : nội soi trung thất, hội chứng chèn ép tĩnh mạch chủ trên

\section{I. ĐẶT VẤN ĐỀ}

Nội soi trung thất sinh thiết từ đường cổ được Carlene báo cáo lần đầu tiên năm $1959{ }^{1}$. Cho đến ngày nay, nội soi trung thất được coi là tiêu chuẩn vàng trong chẩn đoán bản chất các khối u vùng trung thất và được áp dụng rộng rãi ${ }^{2}$. Các khối u vùng trung thất thường có triệu chứng âm thầm. Người bệnh chỉ phát hiện khi u đã to và xâm lấn các cơ quan xung quanh gây các triệu

\footnotetext{
* Khoa Ngoại Lồng Ngưcc, Bệnh viện Chọ Rẫy Người chịu trách nhiệm khoa họ: PGS. TS. Vũ Hũu Vĩnh Ngày nhận bài: 01/05/2018 - Ngày Cho Phép Đăng: 20/05/2018

Phản Biện Khoa học: GS.TS. Bùi Đức Phú PGS.TS. Đặng Ngọc Hùng
} 
chứng trên lâm sàng như : khó thở, ho ra máu... Các khối u vùng thất khi phát triển to sẽ gây chèn ép, xâm lấn các cấu trúc xung quanh, đặc biệt là tĩnh mạch chủ trên và tĩnh mạch vô danh. Trên lâm sàng bệnh nhận sẽ có biểu hiện của hội chứng chèn ép tĩnh mạch chủ trên. Bệnh nhân sẽ xuất hiện các tuần hoàn bàng hệ, tăng tiết đàm nhớt, phù mặt... Tình trạng tuần hoàn bàng hệ này sẽ làm tăng mạch máu quanh khối u và vùng quanh khi quản. Từ đó làm tăng nguy cơ chảy máu trong nội soi trung thất sinh thiết . Ngoài ra tình trạng chèn ép tĩnh mạch chủ trên sẽ ảnh hưởng đến việc gây mê cho bệnh nhân. Theo các báo cáo, tỉ lệ biến chứng khoảng $1-2 \%$ và tỉ lệ thất bại khoảng 4-5\%, độ nhạy và độ đặc hiệu cao trên $95 \%{ }^{3,4}$. Hiện nay, nội soi trung thất sinh thiết đã được thực hiện tại các trung tâm lớn trong cả nước ${ }^{5}$. Tuy vậy, vẫn còn ít các báo cáo về vấn đề này và đặc biệt là việc thực hiện nội soi trung thất sinh thiết trên những bệnh nhân có tình trạng chèn ép tĩnh mạch chủ trên. Chính vì vậy chúng tôi đã thực hiện đề tài này nhằm đánh giá tính khả thi của nội soi trung thất trên những bệnh nhân có hội chứng chèn ép tĩnh mạch chủ trên.

\section{PHƯƠNG PHÁP NGHIÊN CÚU:}

Chúng tôi thực hiện nghiên cứu hồi cứu mô tả cắt ngang có nhóm chứng từ 10/2010 đến 2/2015 tại Khoa Ngoại lồng ngực Bệnh viện Chợ Rẫy trên 81 bệnh nhân được thực hiện phẫu thuật nội soi trung thất sinh thiết chẩn đoán.

Chúng tôi chỉ định nội soi trung thất sinh thiết cho bệnh nhân theo hình ảnh và tính chất khối choán chỗ trung thất

Bệnh nhân được chẩn đoán u trung thất.

- Bệnh nhân có hình ảnh CLĐT ngực u trung thất trước hay trung thất giữa xâm lấn cơ quan quan trọng trong trung thất.

- Bệnh nhân có u trung thất xâm lấn kèm hạch vùng cổ hay vùng khác, đã sinh thiết nhưng vẫn chưa có chẩn đoán xác định.
Bệnh nhân được chẩn đoán u phổi có hạch trung thất vị trí hạch số 2, $4(\mathrm{P}, \mathrm{T}), 7$.

Bệnh nhân được chẩn đoán có hạch trung thất đơn thuần.

- Bệnh nhân được chẩn đoán có hạch trung thất trên CLĐT ngực khi hạch trung thất lớn hơn $1 \mathrm{~cm}$ và có nhiều hơn 2 hạch.

- Bệnh nhân có thể có các hạch vùng khác đi kèm theo. Bệnh nhân có thể đã được sinh thiết hạch các vùng khác làm chẩn đoán nhưng chưa có kết quả giải phẫu bệnh.

Phương pháp phẫu thuật: soi trung thất qua đường mở cổ: đưa ống soi trung thất qua vùng tam giác vô danh nằm giữa thân động mạch cánh tay đầu và động mạch cảnh trái, đi vào vùng trước khí quản và phía dưới quai động mạch chủ, các nhánh của động mạch chủ và tĩnh mạch vô danh. Đường vào này dùng để sinh thiết các $u$ trung thất trước, $u$ trung thất giữa, sinh thiết các hạch quanh khí quản và hạch dưới carina

Bệnh nhân được chẩn đoán có hội chứng tĩnh mạch chủ trên khi có 2 tiêu chuẩn:

1. Lâm sàng: Bệnh nhân có các dấu hiệu: tuần hoàn bàng hệ trên thành ngực, phù mặt, phù 2 chi trên, tăng tiết đàm nhớt,...

2. CT scan: có hình ảnh u xâm lấn, chèn ép làm tắc hoàn toàn tĩnh mạch chủ trên hoặc làm hẹp $>50 \%$ lòng tĩnh mạch chủ trên.

Chúng tôi chia bệnh nhân thành 2 nhóm để phân tích:

1. Nhóm 1: 42 bệnh nhân không có hội chứng tĩnh mạch chủ trên.

2. Nhóm 2: 39 bệnh nhân có hội chứng tĩnh mạch chủ trên.

Tất cả các bệnh nhân đều được phẫu thuật bởi cùng một quy trình phẫu thuật nội soi trung thất sinh thiết và cùng một nhóm phẫu thuật viên. Các biến số thu thấp bao gổm: yếu tố nhân trắc học, biểu hiện lâm sàng, hình ảnh trên CT scan ngực có cản quang, đặc điểm phẫu thuật, thời 
gian thở máy sau mổ, thời gian nằm viện, biến chứng phẫu thuật và tỉ lệ sinh thiết thất bại của cả 2 nhóm bệnh nhân.

Các biến số được thu thập và xử lý bằng phần mềm SPSS 20.0. Các phép kiểm sủ dụng là Chiquare test, Fisher test, T-test, ANOVA.

\section{KẾT QUẢ:}

Từ 10/2010 đến 2/2015, chúng tôi ghi nhận $81 \mathrm{TH}$ và chia làm 2 nhóm

1. Nhóm 1: 42 bệnh nhân không có hội chứng tĩnh mạch chủ trên.

2. Nhóm 2: 39 bệnh nhân có hội chứng tỉnh mạch chủ trên.

Chúng tôi nhận thấy không có khác biệt về giới tính giữa 2 nhóm. Nhóm 2 chủ yếu là u trung thất ác tính xâm lấn, nhóm 1 kết quả chủ yếu là hạch lao và hạch ác tính. Về độ tuổi, nhóm 2 có độ tuổi trung bình lớn hơn nhóm 1 . Trên hình ảnh CT scan, chúng tôi thấy kích thước u lớn hơn, có tình trạng xâm lấn mạch máu nhiều hơn.

Bảng 1 : Đặc điểm lâm sàng của 2 nhóm

\begin{tabular}{|c|c|c|c|c|c|}
\hline & & $\begin{array}{l}\text { Nhóm } 1 \\
\text { (không) } \\
\mathrm{n}=42\end{array}$ & $\begin{array}{l}\text { Nhóm } 2 \\
\mathrm{~N}=39\end{array}$ & Tổng & $\mathrm{p}$ value \\
\hline \multicolumn{6}{|c|}{ Giới tính } \\
\hline & Nam & 32 & 28 & 60 & \multirow[t]{2}{*}{0.652} \\
\hline & Nữ & 10 & 11 & 21 & \\
\hline \multicolumn{2}{|l|}{ Tuổi } & $39.7 \pm 17.9$ & $51.7 \pm 12.6$ & $46 \pm 16.4$ & 0.03 \\
\hline \multicolumn{6}{|c|}{ Lâm sàng } \\
\hline & Ho khan & 28 & 19 & 47 & 0.102 \\
\hline & Ho ra máu & 1 & 7 & 8 & 0.019 \\
\hline & Khó thở & 5 & 14 & 19 & 0.011 \\
\hline & Đau ngực & 29 & 21 & 50 & 0.149 \\
\hline \multicolumn{6}{|c|}{ CT scan ngực } \\
\hline & Kích thước u & $3.77 \pm 2.1$ & $8.67 \pm 3.0$ & $6.19 \pm 3.5$ & 0.006 \\
\hline & Xâm lấn mạch máu & 18 & 33 & 51 & 0.001 \\
\hline & Chèn ép khí quản & 11 & 35 & 46 & 0.001 \\
\hline & $\begin{array}{l}\text { Tăng quang sau } \\
\text { bơm càn quang }\end{array}$ & 40 & 38 & 78 & 0.308 \\
\hline & Giới hạn không rõ & 22 & 38 & 60 & 0.001 \\
\hline \multicolumn{6}{|c|}{ Giải phẫu bệnh } \\
\hline & U trung thất & 9 & 35 & 44 & \multirow[t]{4}{*}{0.001} \\
\hline & Hạch ác tính & 20 & 0 & 20 & \\
\hline & Hạch lao & 12 & 2 & 14 & \\
\hline & Mô liên kết & 1 & 2 & 3 & \\
\hline
\end{tabular}


Về phẫu thuật, chúng tôi nhận thấy khả năng sinh thiết trọn mẫu mô cao hơn ở nhóm 1 $(\mathrm{p}=0.001)$. Về các yếu tố khác trong phẫu thuât, chúng tôi thấy không có sự khác biệt giữa 2 nhóm về thời gian phẫu thuật, kích thước rạch da, mất máu trong mổ. Ở nhóm 2, 1 TH chảy máu nhiều khi sinh thiết do tổn thương thân động mạch cánh tay đầu bên phải cần mở xương ức cầm máu.

Bảng 2: Đặc điểm phẫu thuật 2 nhóm

\begin{tabular}{|c|c|c|c|c|c|}
\hline & & Nhóm 1 & Nhóm 2 & Tổng & $\mathrm{p}$ value \\
\hline Khả năng sinh $t$ & & & & & \\
\hline & Sinh thiết trọn & 21 & 2 & 23 & 0.001 \\
\hline & Sinh thiết 1 phần & 18 & 40 & 58 & \\
\hline Thời gian phẫu & huật & $77.3 \pm 20.7$ & $69.7 \pm 19.9$ & $73.7 \pm 20.6$ & 0.27 \\
\hline Kích thước rạch & & $2.55 \pm 0.6$ & $2.95 \pm 0.6$ & $2.7 \pm 0.7$ & 0.57 \\
\hline Sinh thiết lạnh & & 4 & 9 & 13 & 0.39 \\
\hline Lượng máu mất & & $34.1 \pm 9.5$ & $39.7 \pm 11.2$ & $36.9 \pm 10.7$ & 0.71 \\
\hline Biến chứng & & & & & \\
\hline & Chảy máu & 0 & 1 & 1 & \\
\hline & Tụ dịch vết mố & 1 & 1 & 2 & \\
\hline & Nhiểm trùng vết mổ & 1 & 1 & 2 & \\
\hline
\end{tabular}

Kết quả phẫu thuật, chúng tôi ghi nhận có sự tương đồng giữa 2 nhóm về thời gian thở máy, thời gian nằm viện và tỉ lệ sinh thiết thất bại.

Bảng 3: Kết quả phẫu thuật 2 nhóm

\begin{tabular}{|l|l|l|l|l|}
\hline & Nhóm 1 & Nhóm 2 & Tổng & p value \\
\hline Thở máy sau mố $>6 h$ & 2 & 5 & 7 & 0.21 \\
\hline Số ngày nằm viện & $4.1 \pm 0.4$ & $5.2 \pm 0.9$ & $4.7 \pm 0.6$ & 0.83 \\
\hline Tỉ lệ sinh thiết thất bại & 1 & 2 & 3 & 0.51 \\
\hline
\end{tabular}

\section{BÀN LUẬN:}

Nội soi trung thất từ đường cổ sinh thiết có khoảng không thao tác nhỏ vì vậy biến chứng chảy máu là thường gặp và nguy hiểm nhất. Các $u$ vùng trung thất có tình trạng chèn ép hay xâm lấn tĩnh mạch chủ trên sẽ gây nên hội chứng tĩnh mạch chủ trên. Bệnh nhân sẽ xuất hiện những tuần hoàn bàng hệ vùng dưới da, vùng nền cổ và quanh khí quản. Điều này làm tăng nguy cơ chảy máu trong quá trình bóc tách và sinh thiết $u$. Tác giả Trương Thanh Thiết ${ }^{6}$ ghi nhận biến chứng chảy máu trong mổ chiếm $5,4 \%$ trên nhưng bệnh nhân có tình trạng khối u dính vào các cấu trúc xung quanh và xâm lấn mạch máu. 
Tác giả Ngô Quốc Hưng ${ }^{7}$ báo cáo 170 TH nội soi trung thất sinh thiết cho thấy các yếu tố làm tăng nguy cơ chảy máu : Hội chứng chèn ép $\mathrm{TMC}$ trên (tăng gấp 16 lần), kích thước $\mathrm{u}>5 \mathrm{~cm}$ (tăng 8,2 lần), xâm lấn cấu trúc xung quanh (tăng gấp 13 lần), tăng quang sau bơm càn quang (tăng gấp 9,2 lần) có ý nghĩa thống kê.

Chúng tôi ghi nhận ở nhóm 2 , nhóm có hội chứng TMCT, có kích thước u lớn hơn $(8.67 \pm 3.0$ vs $3.77 \pm 2.1, \mathrm{p}=0.006$ ), xâm lấn mạch máu $(\mathrm{p}=0.001)$ và có giới hạn không rõ $(\mathrm{p}=0.001)$ nhiều hơn nhóm 1. Tuy vậy, trong quá trình sinh thiết lượng máu mất của cả 2 nhóm là tương đương nhau và không có sự khác biệt có ý nghĩa thống kê (34.1 $\pm 9.5 \mathrm{ml}$ vs $39.7 \pm 11.2 \mathrm{ml}, \mathrm{p}=0.71$ ). Ngoài ra chúng tôi cũng ghi nhận không có sự khác biệt thống kê giữa 2 nhóm về thời gian phẫu thuật $(77.3 \pm 20.7$ phút vs $69.7 \pm 19.9$ phút, $\mathrm{p}=0.21$ ).

Ngoài ra, chúng tôi ghi nhận có $1 \mathrm{TH}$ có biến chứng chảy máu ở nhóm 2 do tổn thương thân động mạch cánh tay đầu cần mở xương ức cầm máu. Tác giả Jahangiri ${ }^{8}$ nhận thấy người bệnh có hội chứng chèn ép tĩnh mạch chủ trên khi NSTT có biến chứng nhiều hơn, chủ yếu là chảy máu trong lúc sinh thiết. Nguyên nhân thường gặp là chảy máu do bóc tách và mốc giải phẫu bị đẩy lệch do u to chèn ép.

Tác giả Theodosios Dosios ${ }^{9}$ nghiên cứu đoàn hệ hồi cứu các bệnh nhân được nội soi trung thất sinh thiết, tác giả so sánh trên 39 trường hợp có chèn ép TMC trên với 367 bệnh nhân không có biểu hiện chèn ép TMC trên được nội soi trung thất sinh thiết ghi nhận kết quả: Ở nhóm bệnh nhân có chèn ép TMC trên, tỷ lệ biến chứng là $15,4 \%$, trong đó biến chứng thường gặp là chảy máu chiếm $33,3 \%$, kế đến là biến chứng tắc nghẽn khí quản chiếm 33,3\%. Còn ở nhóm bệnh nhân không có tình trạng chèn ép TMC trên, tác giả ghi nhận tỷ lệ biến chứng là $1,1 \%$ với các biến chứng tương đối nhẹ là nhiễm trùng vết mổ và tổn thương dây thần kinh quặt ngược.

Trong nghiên cứu chúng tôi, chúng tôi nhận thấy không có sự khác biệt có ý nghĩa thống kê giữa thời gian thở máy sau mổ, thời gian nằm viện và tỉ lệ sinh thiết thất bại.

Tỉ lệ sinh thiết thất bại ở nhóm 2 là 2/39 TH. Điều nảy cũng tương tự như các nghiên cứu của Ngô Quốc Hưng ${ }^{5}$ tỉ lệ sinh thiết thất bại là $4.7 \%$. Tác giả Trương Thanh Thiết ${ }^{6}$ và Porte ${ }^{3}$ cũng ghi nhận tương tự, tỉ lệ thất bại $4 \%$. Tác giả Hujala ${ }^{11}$ và Ngô Quốc Hưng ${ }^{7}$ nhận thấy khi u to xâm lấn, chèn ép mạch máu sẽ làm chảy máu trong lúc sinh thiết và làm giảm độ chính xác khi làm sinh thiết.

\section{KẾT LUẬN:}

Nội soi trung thất sinh thiết ở bệnh nhân có hội chứng tĩnh mạch chủ trên là khả thi. Kết quả phẫu thuật và thời gian nằm viện là tương đồng với bệnh nhân không có hội chứng tĩnh mạch chủ trên. Nội soi trung thất ở bệnh nhân có hội chứng tĩnh mạch chủ trên an toàn, tỉ lệ thất bại thấp. Tuy nhiên, cần chú ý vấn đề chảy máu trong lúc sinh thiết ở nhữnh bệnh nhân này.

\section{TÀI LIẸU THAM KHẢO}
1. Carlens
E.

(1959),

"Mediastinoscopy: a method for inspection and tissue biopsy in the superior mediastinum". Dis Chest, 36, pp. 343-52.

2. Ahmad U., Detterbeck C.F (2014), "Diagnostic Evaluation of Anterior Mediastinal Masses and Clinical and Surgical Approach to Thymic Tumors via Sternotomy". Mastery of Cardiothoracic Surgery, Lippincott Williams \& Wilkin, Philadelphia, USA, pp. 124-33.

3. Porte $H$ et al (1998), "The role of mediastinoscopy in the diagnosis of mediastinal lymphadenopathy". Eur J Cardiothorac Surg, 13 (2), pp. 196-9. 
4. Lemaire A. et al (2006), "Nine-year single center experience with cervical mediastinoscopy: complications and false negative rate". Ann Thorac Surg,, 82 (4), pp. 1185-9.

5. Ngô Quốc Hưng, Vũ Hữu Vĩnh, Lê Nữ Thị Hòa Hiệp (2017), "Vai trò của nội soi trung thất từ đường cổ trong chẩn đoán bản chất các khối u và hạch vùng trung thất", Tạp chi Phẫu Thuật Tim mạch và Lồng Ngục Việt Nam, (16), tr. 52-32

6. Trương Thanh Thiết, Nguyễn Hoài Nam (2016), "Vai trò hiện nay của nội soi trung thất chẩn đoán bệnh lý hạch trung thất". Y Học Thành Phố Hồ Chí Minh, 5(20), tr. 120-5.

7. Jahangiri M, Taggart DP, Goldstraw P (1993), "Role of mediastinoscopy in superior vena cava obstruction". Cancer, 71 (10), pp. 3006-8

8. Dosios T. et al (2005), "Cervical Mediastinoscopy and anterior mediastinotomy in superior vena cava obstruction". Chest, 128 (3), pp. 1551-6.

9. Mineo T. C., Ambrogi V., Nofroni I., Pistolese C. (1999), "Mediastinoscopy in superior vena cava obstruction: analysis of 80 consecutive patients". The Annals of Thoracic Surgery, 68 (1), pp. 223-6.

10. Hujala K. T., Sipilä J. I., Grénman R. (2001), "Mediastinoscopy-its role and value today in the differential diagnosis of mediastinal pathology". Acta Oncologica, 40 (1), pp. 79-82. 